\title{
Adult Spinal Deformity Over 70 Years of Age: A 2-Year Follow-Up Study
}

\author{
CEM KARABULUT, MD,${ }^{1 *}$ SELIM AYHAN, MD,${ }^{1,2^{*}}$ SELCEN YUKSEL, PHD,${ }^{3}$ VUGAR NABIYEV, MD,${ }^{1}$ \\ ALBA VILA-CASADEMUNT, PHD,${ }^{4}$ FERRAN PELLISE, MD, PHD ${ }^{4}$ AHMET ALANAY, MD,${ }^{5}$ \\ FRANCISCO JAVIER SANCHEZ PEREZ-GRUESO, MD,${ }^{6}$ FRANK KLEINSTUCK, MD, ${ }^{7}$ IBRAHIM OBEID, \\ MD ${ }^{8}$ EMRE ACAROGLU, MD, ${ }^{9}$ EUROPEAN SPINE STUDY GROUP ${ }^{4}$ \\ ${ }^{1}$ ARTES Spine Center, Ankara, Turkey, ${ }^{2}$ Acibadem Mehmet Ali Aydinlar University, Istanbul, Turkey, ${ }^{3}$ Yildirim Beyazit University, Department of Biostatistics, \\ Ankara, Turkey, ${ }^{4}$ Hospital Universitari Vall d'Hebron, Barcelona, Spain, ${ }^{5}$ Acibadem Mehmet Ali Aydinlar University, Department of Orthopaedics and \\ Traumatology, Istanbul, Turkey, ${ }^{6}$ Hospital Universitari La Paz, Madrid, Spain, ${ }^{7}$ Schulthess Klinik, Zürich, Switzerland, ${ }^{8}$ Bordeaux University Hospital, \\ Bordeaux, France, ${ }^{9}$ Ankara Spine Center, Ankara, Turkey
}

\begin{abstract}
Background: Treatment of adult spinal deformity (ASD) in elderly patients remains controversial. The aim of this study was to identify the factors leading to the surgical treatment by comparing the baseline characteristics of operative versus nonoperative patients, to evaluate the safety and efficacy of surgery, and to compare operative and nonoperative management of elderly ASD patients at the end of the 2-year follow-up period.

Methods: Retrospective review of a multicenter, prospective ASD database was performed. Patients over 70 years of age with ASD who were scheduled to undergo surgical treatment and who were treated and/or followed without surgical intervention participated in the study. Demographic, clinical, surgical, and radiological characteristics and health-related quality-of-life (HRQOL) (Core Outcome Measures Index [COMI], Oswestry Disability Index [ODI], Short-Form-36 Mental Component Summary [SF-36 MCS], Short-Form-36 Physical Component Summary [SF36PCS], and Scoliosis Research Society-22 [SRS-22]) parameters of such group of patients were evaluated pre- and posttreatment.

Results: A total 90 patients (females: 71, males: 29; operative: 61, nonoperative: 29) made up the study group. The comparison between the operative and the nonoperative groups at baseline showed statistical significance for all the HRQOL parameters and the major coronal Cobb angle $(P<.05)$. The calculated optimal cutoff values to diverge operative and nonoperative groups for COMI, ODI, SF-36 PCS, and SRS-22 were 5.7, 37.0, 37.5, and 3.2, respectively $(P<.05)$. All operative patients were treated with posterior surgery. Overall, 135 complications ( 71 major, 64 minor) and 1 death were observed. Surgically treated patients were found to be improved both clinically and in HRQOL parameters 2 years after surgery for all HRQOL parameters except SF-36 MCS, even in the presence of complications $(P<.05)$, while nonoperative patients have not changed or deteriorated at the end of 2 years.

Conclusions: Despite a relatively high incidence of complications, the likelihood of achieving a clinically significant and relevant HRQOL improvement was superior for patients who were treated surgically in the present population.
\end{abstract}

Other and Special Categories

Keywords: adult spinal deformity, complications, elderly, nonoperative, outcomes, surgery, treatment

\section{INTRODUCTION}

The growth of the aging population and longer life expectancy and the increased awareness of quality-of-life issues have made adult spinal deformity (ASD) a significant health care concern. ${ }^{1}$ The ASD population is indeed reasonably heterogeneous at presentation and should better be evaluated in different age-groups and possibly diagnosis. ${ }^{2}$ Although the patients characteristically present with

* These authors contributed equally to this work. pain and disability, first-line management for symptomatic ASD without a progressive neurological deficit typically involves nonoperative treatment options, such as physical therapy, steroid injections, nonsteroidal anti-inflammatory drugs, and narcotic analgesics, to avoid the potential morbidity of an extensive surgical intervention. ${ }^{3,4}$ However, a group of patients with progressive pain, disability, and neurological problems warrant a decision on surgical treatment. ${ }^{4-7}$ When compared with nonoperative treatment strategies, surgery provides significant symptom relief but with reported complication rates 
ranging from $10 \%$ to more than $80 \% .^{4,5,7-9}$ Therefore, a substantial proportion of operated patients may not potentially benefit from surgery regardless of the recent technical advances in ASD surgery. $5,7,10$

Estimating the effects of complications on the outcomes of treatment in ASD, primarily for surgical therapy in the elderly population, remains a significant challenge. This challenge has the potential of skewing decision making, mainly because of the perceptions that this group of patients is more prone to complications, because complications severely affect the outcomes negatively, and because these patients do not benefit from the surgical treatment anyway. Surgery-related factors, such as blood loss, surgical time, length of hospital stay, and length of overall recovery, as well as complication rates, may be reasonably high in these patients. ${ }^{11}$ Analyzing the results of surgery in elderly patients reveals that the complication rates are indeed higher when compared to their younger counterparts and alternative treatment modalities. ${ }^{12-14}$ In addition, more than $30 \%$ of these surgically treated elderly patients may require revision surgery within 5 years following the index procedure. $^{11}$

Several recent papers have particularly reported on the effects of complications on treatment outcomes in such groups of patients. Daubs et $\mathrm{al}^{12}$ have investigated the complications and outcomes of 46 patients over the age of 60 who underwent thoracic or lumbar arthrodesis of 5 or more levels with a mean follow-up of 4.2 years. They concluded that the overall complication rate in this patient population was $37 \%$ (with a major complication rate of $20 \%$ ), and patients over the age of 69 years had yet higher complication rates. In spite of this, clinical outcomes at final follow-up were significantly improved in Oswestry Disability Index (ODI) scores. Likewise, a study by the European Spine Study Group focusing on spinal osteotomies in ASD patients has demonstrated that complications do not necessarily affect the clinical outcomes in this subpopulation of patients who had undergone osteotomies. ${ }^{15}$ On the other hand, Glassman et al, ${ }^{16}$ reporting on the effect of treatment complication on 46 adult deformity patients undergoing surgery, demonstrated that major complications have adversely affected the outcome, as evidenced by the SF-12 general health scores at 1 year followup. In another study, Scheer et $\mathrm{al}^{14}$ have investigated the effect of complications on the recovery of patients using an integrated health score and concluded that there was a significantly protracted mental recovery phase associated with patients who had at least 1 complication as well as either a minor and a major complication. The addition of a reoperation also adversely affected the mental recovery as well as overall satisfaction. Finally, Sciubba et $\mathrm{al}^{17}$ have focused explicitly on patients with ASD over 75 years and have demonstrated that surgery could provide significant improvements in pain and disability over a 2-year period. Furthermore, when compared to the nonoperative cohort of elderly patients managed over a similar period, surgical patients had significantly improved healthrelated quality-of-life (HRQOL) measurements over baseline values. Also, operative patients were more likely to reach minimal minimum clinically important difference (MCID) than nonoperative patients. Based on this literature background, there is still insufficient evidence to draw general conclusions in patients with ASD over 70 years of age.

This study aims to do the following:

- Identify the factors leading to the surgical treatment by comparing the baseline characteristics of operative versus nonoperative patients with adult spinal deformity over 70 years of age

- Evaluate the safety of surgical treatment by analyzing the rate and severity of complications

- Compare the HRQOL-based clinical results of operative and nonoperative management of patients (surgical patients further stratified by the presence or absence of complications) at the 2-year follow-up

\section{METHODS}

A retrospective review of prospectively collected data from a multicenter database on ASD was performed. The inclusion criteria into the database were age $>18$ years and scoliosis $>20^{\circ}$, or sagittal vertical axis (SVA) $>5 \mathrm{~cm}$, or pelvic tilt $>25^{\circ}$, or thoracic kyphosis $>60^{\circ}$. All patients were enrolled into an institutional review board-approved protocol by the respective sites. Specifically, for the present study, consecutive patients over 70 years of age with spinal deformities who were scheduled to undergo surgical treatment and who were treated and/or followed without surgical intervention were included. Demographic (age, gender, comorbidi- 
ties, and body mass index), clinical, surgical (Adult Deformity Surgery Complexity Index, ${ }^{18}$ duration of surgery, estimated blood loss, technical aspects [anterior, posterior, the occurrence of osteotomies and interbody fusions, number of fused vertebral segments], intensive care unit stay, and length of hospitalization), radiological features (SVA, T2T12 kyphosis, major coronal curve Cobb angle, lordosis gap, ${ }^{19}$ global tilt, ${ }^{20} \mathrm{~T} 1$ sagittal tilt, SRS Schwab coronal curve type) and HRQOL (Core Outcome Measures Index [COMI], Oswestry Disability Index [ODI], Short-Form-36 Mental Component Summary [SF-36 MCS], Short-Form-36 Physical Component Summary [SF-36 PCS], and Scoliosis Research Society-22 questionnaire [SRS22]) parameters of this population were evaluated pre- and posttreatment.

In order to interpret improvements in HRQOL parameters in a clinically relevant fashion, minimum detectable change (MDC) and MCID values were calculated. The overall MDC and MCID scores of HRQOL parameters that were obtained from our multicenter ASD database for both surgical and nonsurgical patients as 1.32 and 1.99 for COMI, 11.11 and 10.14 for ODI, 5.33 and 4.93 for SF-36 PCS, and 0.46 and 0.53 for SRS-22, respectively. ${ }^{21}$ In addition, MCID values from literature, that is, for ODI (-15), SF-36 PCS (+5.2), COMI (-2.2), and SRS-22 (0.4), were also taken into consideration to allow for the heterogeneity of our population. ${ }^{2,17,19,22-25}$

Indications for surgery were up to the discretion and decision of the treating physician but mainly the presence of neurological deterioration, rigid coronal and/or sagittal deformity, or progressive pain and disability. Peri- and postoperative complications, classified as major (life threatening or requiring additional surgery) or minor, were also investigated for their effects on HRQOL parameters at 2-year follow-up. Although the treatment of the nonoperative group was heterogeneous, this group was followed up in the same manner as dictated by the database rules for surgical patients of institutions included in the study.

\section{Statistical Analysis}

Demographical, clinical, radiological, and surgical variables, as well as HRQOL parameters, were set as independent variables for the $t$ test, chi-square test, and the multivariate binary logistic regression model, adjusted receiver operating characteristic
(ROC) analysis, and analysis of variance (ANOVA) as appropriate.

To compare operative and the nonoperative groups at baseline, the $t$ test was used for continuous independent variables, and the chisquare test was used for categorical variables. The type I error rate was taken as $\alpha=0.05$ for statistical significance.

To measure the influence of the demographic, clinical, radiological, and HRQOL measurements on operative and nonoperative groups of patients at baseline, univariate analyses from first step were used to select the candidate variables to be defined as the dependent variable. The type I error rate was taken as $\alpha=0.25$ for statistical significance for candidate variables. A stepwise method was used for model selection. For the final step, type I error rate was again taken as $\alpha=0.05$.

For the scales that had been defined as statistically significant following multivariate binary logistic regression analysis, retrospective cutoff points were determined as the predictors of why the patient had gone to the operative or nonoperative group. An adjusted ROC estimation was used to get optimal cutoffs based on the results of the multivariate logistic regression analysis. Two-way mixed ANOVA was used to compare the surgically treated patients with or without complications and the nonoperative group by the difference between baseline and second-year HRQOL measurement changes.

The influence of surgical complexity on HRQOL parameters and complications were statistically analyzed by using the Spearman correlation coefficient and point-biserial correlation, respectively.

All statistical analysis was performed using the SPSS Statistics version 21.0 software (IBM Corp., Armonk, New York).

\section{RESULTS}

At the time of this study, our database had a total of 181 patients (females: 151, males: 30) for operative $(\mathrm{n}=85)$ and nonoperative $(\mathrm{n}=96)$ groups over 70 years of age. Of these, 90 patients (females: 71, males: 19; operative: 61 [72\%], nonoperative: 29 [30\%]) had 2-year follow-up.

Demographic, clinical, radiological, and HRQOL parameters of these patients are summarized in Tables 1 and 2. Comparison between operative and nonoperative groups at baseline showed statistically significant differences for all the HRQOL parame- 
Table 1. Baseline demographic and radiographic characteristics of patients: comparison of continuous variables between operative (Op) and nonoperative (Non-Op) groups.

\begin{tabular}{|c|c|c|c|c|c|}
\hline Variable & Groups & $\mathbf{n}$ & Mean & $\begin{array}{l}\text { Standard } \\
\text { Deviation }\end{array}$ & $P$ \\
\hline \multirow[t]{2}{*}{ Age (y) } & Non-Op & 96 & 75.84 & 4.53 & .328 \\
\hline & Op & 85 & 75.21 & 4.10 & \\
\hline \multirow[t]{2}{*}{ BMI $\left(\mathrm{kg} / \mathrm{m}^{2}\right)$} & Non-Op & 92 & 26.34 & 4.50 & .710 \\
\hline & Op & 80 & 26.61 & 4.96 & \\
\hline \multirow[t]{2}{*}{ Back pain VAS $(\mathrm{cm})$} & Non-Op & 94 & 6.22 & 2.22 & .308 \\
\hline & $\mathrm{Op}$ & 84 & 6.57 & 2.32 & \\
\hline \multirow[t]{2}{*}{ Leg pain VAS (cm) } & Non-Op & 94 & 3.85 & 3.19 & .015 \\
\hline & Op & 84 & 5.05 & 3.27 & \\
\hline \multirow[t]{2}{*}{ COMI score } & Non-Op & 66 & 5.44 & 2.26 & $<.001$ \\
\hline & Op & 69 & 7.20 & 1.45 & \\
\hline \multirow[t]{2}{*}{ ODI } & Non-Op & 95 & 39.22 & 17.80 & $<.001$ \\
\hline & $\mathrm{Op}$ & 84 & 50.90 & 15.22 & \\
\hline \multirow[t]{2}{*}{ SF-36 MCS } & Non-Op & 93 & 45.82 & 11.93 & .004 \\
\hline & Op & 81 & 40.35 & 12.98 & \\
\hline \multirow[t]{2}{*}{ SF-36 PCS } & Non-Op & 93 & 36.32 & 8.57 & .006 \\
\hline & Op & 81 & 33.03 & 6.87 & \\
\hline \multirow[t]{2}{*}{ SRS-22 } & Non-Op & 93 & 3.11 & 0.66 & $<.001$ \\
\hline & Op & 81 & 2.72 & 0.58 & \\
\hline \multirow{4}{*}{$\begin{array}{l}\text { Major coronal curve } \\
\text { Cobb angle }\left({ }^{\circ}\right) \\
\text { Global tilt }\left({ }^{\circ}\right)^{19}\end{array}$} & Non-Op & 87 & 37.09 & 17.56 & $<.001$ \\
\hline & Op & 85 & 25.91 & 14.92 & \\
\hline & Non-Op & 83 & 36.59 & 13.50 & .919 \\
\hline & Op & 80 & 36.81 & 14.29 & \\
\hline \multirow[t]{2}{*}{ Lordosis gap $\left({ }^{\circ}\right)^{18}$} & Non-Op & 90 & 25.16 & 16.11 & .726 \\
\hline & Op & 83 & 24.30 & 16.15 & \\
\hline \multirow{2}{*}{ Lumbar lordosis $\left({ }^{\circ}\right)$} & Non-Op & 93 & 41.29 & 17.05 & .885 \\
\hline & $\mathrm{Op}$ & 84 & 41.68 & 18.83 & \\
\hline \multirow[t]{2}{*}{ Pelvic incidence $\left(^{\circ}\right)$} & Non-Op & 91 & 58.14 & 13.40 & .100 \\
\hline & $\mathrm{Op}$ & 83 & 61.66 & 14.69 & \\
\hline \multirow[t]{2}{*}{ Pelvic tilt $\left({ }^{\circ}\right)$} & Non-Op & 91 & 28.46 & 9.98 & .725 \\
\hline & $\mathrm{Op}$ & 83 & 27.94 & 9.50 & \\
\hline \multirow[t]{2}{*}{ Sacral slope $\left({ }^{\circ}\right)$} & Non-Op & 92 & 31.02 & 11.07 & .175 \\
\hline & $\mathrm{Op}$ & 83 & 33.48 & 12.84 & \\
\hline \multirow{2}{*}{$\begin{array}{l}\text { Sagittal balance } \\
\text { (SVA) }(\mathrm{mm})\end{array}$} & Non-Op & 80 & 71.59 & 47.01 & .340 \\
\hline & $\mathrm{Op}$ & 80 & 79.34 & 55.03 & \\
\hline \multirow[t]{2}{*}{ T1 sagittal tilt $\left(^{\circ}\right)$} & Non-Op & 80 & 4.15 & 3.61 & .575 \\
\hline & Op & 80 & 4.49 & 4.07 & \\
\hline \multirow[t]{2}{*}{ T2-T12 kyphosis $\left({ }^{\circ}\right)$} & Non-Op & 84 & 44.92 & 17.88 & .174 \\
\hline & Op & 81 & 41.09 & 18.05 & \\
\hline
\end{tabular}

Abbreviations: BMI, body mass index; VAS, visual analog scale; COMI, Core Outcome Measures Index; ODI, Oswestry Disability Index; SF-36 MCS, ShortForm-36 Mental Component Summary; SF36-PCS, Short-Form-36 Physical Component Summary; SRS-22, Scoliosis Research Society-22; SVA, sagittal vertical axis.

Table 2. Baseline demographic and radiographic characteristics of patients: comparison of categorical variables between operative (Op) and nonoperative (Non-Op) groups. Statistical significance $(P<.05)$ is indicated by bold.

\begin{tabular}{clrl}
\hline Variable & Groups & n (\%) & $\boldsymbol{P}$ \\
\hline Gender & & & \\
Female & Non-Op & $78(81.3)$ & .403 \\
& Op & $73(85.9)$ & \\
Male & Non-Op & $18(18.7)$ & \\
& Op & $12(14.1)$ & \\
SRS-22-Schwab curve type (coronal) & & \\
D & Non-Op & $19(20.4)$ & $\mathbf{. 0 1 7}$ \\
& Op & $5(5.9)$ & \\
L & Non-Op & $33(35.5)$ & \\
& Op & $28(32.9)$ & \\
N & Non-Op & $39(41.9)$ & \\
& Op & $51(60.0)$ & \\
T & Non-Op & $2(2.2)$ & \\
& Op & $1(1.2)$ & \\
\end{tabular}

Abbreviation: SRS-22, Scoliosis Research Society-22. ters, leg pain, and only for coronal radiological variables (major coronal curve Cobb angle, SRS Schwab coronal curve type) (Tables 1 and 2).

Multivariate logistic regression analyses for the effects of HRQOL measurements at baseline on the decision for surgery are presented in Table 3. All HRQOL measures were found to significantly affect this decision with odds ratios of 1.618, 1.042, 0.968, 0.942, and 0.332 for COMI, ODI, SF-36 MCS, SF36 PCS, and SRS-22, respectively. Calculated optimal cutoff values for HRQOL parameters to differentiate between operative and nonoperative groups were 5.68 for COMI, 37.00 for ODI, 37.46 for SF-36 PCS, and 3.17 for SRS-22 (Table 4).

The characteristics of 61 (females: 46, males: 15) surgically treated patients with 2 year follow-up and a summary of the surgical features are summarized in Table 5. All patients were treated with posterior surgery. A total of 39 osteotomies and 24 interbody fusions were performed in order (or attempting) to achieve an adequate amount of correction for an acceptable coronal and/or sagittal balance. Overall, 135 complications (71 major, 64 minor) in 47 patients $(77 \%)$ and 1 death were observed $(1.63 \%)$ (Table 6). The reoperation rate was calculated as $62.3 \%(38 / 61)$ at the end of 2-year follow-up period. No statistically significant correlation between the complexity of surgery and complications was found $(P>.05)$ (Table 7).

Table 8 summarizes the effect of treatment on HRQOL parameters, including a separate setting of these patients with complications, at baseline, and 2 years after the treatment, with patients grouped as "operative without complications," "operative with complications," and "nonoperative." For all HRQOL measurements except SF-36 MCS, surgically treated patients significantly improved by means of HRQOL parameters 2 years after the surgery even in the presence of complications $(P<.05)$, and the nonoperative patients did not change or significantly deteriorated at the end of 2 years (latter for ODI) $(P<.05)$ (Figure $1 \mathrm{~A}-\mathrm{E})$. On the other hand, HRQOL parameters were not influenced by the complexity of ASD surgery $(P>.05)$ (Table 7).

\section{DISCUSSION}

This study perfectly demonstrates that the clinical outcomes of the patients treated surgically after a 2year follow-up period, even in the presence of complications, were better than those followed up 
Table 3. Multivariate logistic regression results for health-related quality-of-life (HRQOL) parameters. For each HRQOL parameter, the parameter itself at baseline was entered as the primary variable, whereas the secondary variables consisted of the magnitude of the thoracolumbar curve at baseline (as the strongest correlate) and a statistical constant (not shown at the table).

\begin{tabular}{|c|c|c|c|c|c|c|c|c|}
\hline & \multirow[b]{2}{*}{ B } & \multirow[b]{2}{*}{ SE } & \multirow[b]{2}{*}{ Wald } & \multirow[b]{2}{*}{ df } & \multirow[b]{2}{*}{$P$} & \multirow[b]{2}{*}{ OR } & \multicolumn{2}{|c|}{$95 \%$ CI for OR } \\
\hline & & & & & & & Lower & Upper \\
\hline COMI score baseline & .481 & .118 & 16.635 & 1 & $<.001$ & 1.618 & 1.284 & 2.040 \\
\hline ODI baseline & .041 & .011 & 13.253 & 1 & $<.001$ & 1.042 & 1.019 & 1.065 \\
\hline SF-36 MCS baseline & -.032 & .014 & 5.296 & 1 & .021 & .968 & .942 & .995 \\
\hline SF-36 PCS baseline & -.060 & .022 & 7.234 & 1 & .007 & .942 & .901 & .984 \\
\hline SRS-22 baseline & -1.102 & .296 & 13.870 & 1 & $<.001$ & .332 & .186 & .593 \\
\hline
\end{tabular}

Abbreviations: df, degrees of freedom; OR, odds ratio; CI, confidence interval; COMI, Core Outcome Measures Index; ODI, Oswestry Disability Index; SF-36 MCS, Short-Form-36 Mental Component Summary; SF36-PCS, Short-Form-36 Physical Component Summary; SRS-22, Scoliosis Research Society-22.

without surgical treatment. Certainly, the comparison of the results of the heterogeneous structure of the overall ASD population and further attempts for a comparison of the results of 2 statistically different groups can lead to criticism of the interpretation of the obtained data. Although we earlier mentioned that "the indications for surgery were up to the discretion and the decision of the treating physician and the patient," a reality is the fact that the parameters causing the statistical difference between the baseline values of the 2 groups were among the main factors for such a decision. Factors that may be effective in providing the surgical decision in the patient population from the database of the study were provided from a retrospective analysis of a multicenter database. The improvement of HRQOL parameters at the end of 2 years and their comparison with the baseline values of the very same patients when the surgically treated group is the case, as well as and the further steadiness or mild improvement of the similar data for those who were not surgically treated when the same comparison was performed, clearly demonstrate that the decision-making mechanism worked correctly, and the results of the study would contribute to the existing literature.

In depth, this study analyzed the HRQOL cutoff levels for the decision of surgery as well as the surgical complications and their effects on HRQOL in a population of ASD patients older than 70 years of age treated surgically or nonsurgically with a 2-year follow-up. Our results suggest that it is possible to define specific cutoff points in all HRQOL measures except SF-36 MCS with strong statistical significance. Further, despite being prone to a high risk of complications (47 patients with 135 complications out of 61 patients, or $77.05 \%$ ), surgery yielded better chances of improvement (again, except for SF-36 MCS) even in the patient group that sustained complications at the end of 2-year follow-up period.

This study is not the first to address the challenge of performing spinal deformity surgery in elderly adults. Scuibba et $a l^{17}$ have recently published the results of ASD patients over 75 years of age who had had surgical treatment. The findings of our study are similar to theirs in that their study has also demonstrated that surgery was more likely to achieve detectable improvements despite a similarly high complication rate ( 9 patients with 24 complications out of 12 surgical patients, or $75 \%$ ). On the other hand, our study is unique in being by far the largest reporting on this age-group and in further analyzing the potential HRQOL parameter cutoff points. Specific analyses of these are essential for understanding the factors that contribute to decision making in the treatment of ASD in this somewhat extreme population.

It is intuitive to think that the decision for surgery would be affected by the HRQOL of the patients, and our findings have reiterated this (Table 3). On the

Table 4. Optimal cutoff points of health-related quality-of-life parameters that significantly diverge operative and nonoperative patient groups. Statistical significance $(P<.05)$ is indicated by bold.

\begin{tabular}{|c|c|c|c|c|c|c|}
\hline & $\mathbf{A U C}$ & $95 \%$ CI of $\mathrm{AUC}$ & $P$ & Optimal Cutoff & Sensitivity & Specificity \\
\hline COMI & 0.78 & $0.72-0.84$ & $<.001$ & 5.68 & 0.90 & 0.56 \\
\hline ODI & 0.71 & $0.65-0.76$ & $<.001$ & 37.00 & 0.86 & 0.53 \\
\hline $\mathrm{SF}-36 \mathrm{MCS}$ & 0.44 & $0.38-0.51$ & $>.05$ & - & - & - \\
\hline SF-36 PCS & 0.68 & $0.64-0.74$ & $<.001$ & 37.46 & 0.59 & 0.55 \\
\hline SRS-22 & 0.75 & $0.70-0.79$ & $<.001$ & 3.17 & 0.79 & 0.52 \\
\hline
\end{tabular}

Abbreviations: AUC, area under receiver operating characteristic curve adjusted by the constant parameter; CI, confidence interval; COMI, Core Outcome Measures Index; ODI, Oswestry Disability Index; SF-36 MCS, Short-Form-36 Mental Component Summary; SF36-PCS, Short-Form-36 Physical Component Summary; SRS-22, Scoliosis Research Society-22. 
Table 5. Characteristics of surgical patients with 2-year follow-up.

\begin{tabular}{lcc}
\hline Value & $\mathbf{n}(\mathbf{\% )}$ & $\begin{array}{c}\text { Median } \\
\text { (Min-Max) }\end{array}$ \\
\hline Patient characteristics & & \\
Etiology & $42(68.9)$ & \\
$\quad$ Degenerative & $10(16.4)$ & \\
$\quad$ Idiopathic & $6(9.8)$ & \\
$\quad$ Failed-back & $3(4.9)$ & \\
$\quad$ Others & & \\
No. of comorbidities & 24 & \\
$\quad$ Hypertension & 12 & \\
$\quad$ Depression & 6 & \\
$\quad$ Heart disease & 27 & \\
$\quad$ Anemia & & \\
$\quad$ Others & & \\
Surgical characteristics & & $21.7(1-61)$ \\
ADSCI & & $1600(150-5600)$ \\
Surgical time (min) & & \\
Estimated blood loss (mL) & & \\
No. of patients with osteotomy & $39(62.9)$ & $(1-18)$ \\
No. of patients with interbody fusion & $24(38.7)$ & \\
Number of levels fused & & \\
Intensive care unit stay (hours) & 47 patients & $24(6-120)$ \\
Length of hospitalization (days) & $(75.8)$ & \\
\hline
\end{tabular}

Abbreviation: ADSCI, Adult Spinal Deformity Surgery Complexity Index.

a Others: neuromuscular and posttraumatic.

bOthers: arthritis, blood clotting disorders, cancer, chronic alcoholism, diabetes, kidney disease, liver disease, lung disease.

other hand, it is interesting that for the HRQOL parameters that demonstrated definitive cutoff points for the decision of surgery (ODI, COMI, SF-36 PCS, and SRS-22), these points are consistent with relatively mild to moderate levels of impairment and/or disability (Table 4). At the time this analysis was started, the authors had indeed hypothesized that this might have been plausible for only SRS-22; that is, the test may be considered as being not necessarily specific for disability, as it measures appearance and self-perception along with impairment and pain, theoretically minor concerns over 70 years of age. Therefore, SRS-22 may not be the appropriate HRQOL parameter to assess function in this agegroup. It thus appears that this hypothesis has been wrong. In terms of discriminating surgical patients, SRS-22 is now proven to be as useful as the other measures of (physical) impairment. Then and again, how can we explain the relatively low impairment levels as surgical cutoff points? Two potential (and probable) reasons may be stated. First, the cutoff value levels may not be as low as we think they are. Similar values have not been investigated and defined in the general ASD population or any other age subgroups within that population, so these values may be pretty much consistent with the similar values for these populations. As our improvement rates and knowledge base from other studies ${ }^{9}$ suggest, there is probably no reason to think that decision making in
Table 6. List and incidence of surgical complications classified as major and minor (major defined as a complication that threatens life or function or requiring additional surgery or readmission to hospital).

\begin{tabular}{|c|c|}
\hline Complications & $\mathbf{n}$ \\
\hline \multicolumn{2}{|l|}{ Major } \\
\hline \multicolumn{2}{|l|}{ Intraoperative } \\
\hline Nerve root/spinal cord injury & 7 \\
\hline Vascular injury & 1 \\
\hline Excessive blood loss & 4 \\
\hline Vertebral body fracture & 1 \\
\hline \multicolumn{2}{|l|}{ Postoperative } \\
\hline Acute respiratory distress syndrome & 1 \\
\hline Pulmonary embolism & 1 \\
\hline Cholecystitis & 1 \\
\hline Ileus & 2 \\
\hline Sepsis & 2 \\
\hline Death & 1 \\
\hline $\begin{array}{l}\text { Others (reintubation, pulmonary, } \\
\text { congestive heart failure, renal failure) }\end{array}$ & 7 \\
\hline \multicolumn{2}{|l|}{ Follow-up } \\
\hline Instrumentation and/or junctional failure & 35 \\
\hline Infection-deep & 7 \\
\hline Other medical & 2 \\
\hline \multicolumn{2}{|l|}{ Minor } \\
\hline \multicolumn{2}{|l|}{ Intraoperative/postoperative } \\
\hline Dural tear & 9 \\
\hline Pain/radiculopathy/sensory deficit & 7 \\
\hline Infection-superficial & 2 \\
\hline Pleural effusion & 2 \\
\hline Nonspinal infection & 6 \\
\hline Minor cardiopulmonary problems & 3 \\
\hline Other medical & 3 \\
\hline \multicolumn{2}{|l|}{ Follow-up } \\
\hline Wound dehiscence_-seroma & 6 \\
\hline Instrumentation and/or junctional problem & 26 \\
\hline Complication frequency & $\begin{array}{l}\text { No. of } \\
\text { Patients }\end{array}$ \\
\hline 1 & 16 \\
\hline 2 & 10 \\
\hline 3 & 10 \\
\hline 4 & 3 \\
\hline 5 & 4 \\
\hline $6+$ & 4 \\
\hline
\end{tabular}

older patients need be substantially different. Second, this group of patients (and kin) may even be more sensitive to functional impairment than the other agegroups because of social factors (loss of partner, risk of institutionalization) and medical factors (increased number of comorbidities, a heavier burden of life) and therefore may be more prone to elect surgical

Table 7. The relationship between the adult deformity surgical complexity and complications as well as health-related quality-of-life parameters.

\begin{tabular}{ccccccc}
\hline Value & Complications & COMI & ODI & $\begin{array}{c}\text { SF-36 } \\
\text { MCS }\end{array}$ & $\begin{array}{c}\text { SF-36 } \\
\text { PCS }\end{array}$ & SRS-22 \\
\hline ADSCI & & & & & & \\
Rho & $-0.028^{\mathrm{a}}$ & $-0.096^{\mathrm{b}}$ & $-0.008^{\mathrm{b}}$ & $0.036^{\mathrm{b}}$ & $-0.057^{\mathrm{b}}$ & $0.020^{\mathrm{b}}$ \\
$P$ & .808 & $.614^{2}$ & $.962^{2}$ & .834 & .741 & .906 \\
\hline
\end{tabular}

Abbreviations: COMI, Core Outcome Measures Index; ODI, Oswestry Disability Index; SF-36 MCS, Short-Form-36 Mental Component Summary; SF36-PCS,

Short-Form-36 Physical Component Summary; SRS-22, Scoliosis Research

Society-22; ADSCI, Adult Deformity Surgery Complexity Index.

${ }^{\text {a }}$ Point-biserial correlation.

${ }^{\mathrm{b}}$ Spearman correlation coefficient. 
Table 8. Changes in health-related quality-of-life (HRQOL) parameters from baseline to second-year time points for "operative group with complications," "operative group without complications," and "nonoperative group." Corresponding schematics of change in scores over 2 years can be seen in Figure 1a-e. Statistical significance $(P<.05)$ is indicated by bold. Letters indicate statistical significance $(P<.05)$ for comparison in and between groups.

\begin{tabular}{|c|c|c|c|c|}
\hline HRQOL Parameters & Groups & Baseline & Second Year & $P$ \\
\hline \multirow[t]{3}{*}{ COMI (Figure 1A) } & Operative group without complications & $7.36 \pm 1.12^{\mathrm{a}}$ & $3.75 \pm 2.44^{\mathrm{a}}$ & $.001^{\mathrm{a}}$ \\
\hline & Operative group with complications & $6.53 \pm 1.81^{\mathrm{b}}$ & $4.38 \pm 3.28^{\mathrm{b}}$ & $.007^{\mathrm{b}}$ \\
\hline & Nonoperative group & $5.65 \pm 2.82$ & $4.97 \pm 3.70$ & \\
\hline \multirow{3}{*}{ ODI (Figure 1B) } & Operative group without complications & $47.00 \pm 12.74^{\mathrm{a}, \mathrm{c}}$ & $26.11 \pm 14.38^{\mathrm{a}}$ & $<.001^{\mathrm{a}}$ \\
\hline & Operative group with complications & $50.84 \pm 16.32^{\mathrm{b}}$ & $41.50 \pm 22.24^{\mathrm{b}}$ & $.001^{\mathrm{b}}$ \\
\hline & Nonoperative group & $38.09 \pm 17.10^{\mathrm{c}}$ & $39.40 \pm 20.32$ & $.018^{\mathrm{c}}$ \\
\hline \multirow[t]{3}{*}{ SF-36 MCS (Figure 1C) } & Operative group without complications & $41.98 \pm 11.24$ & $42.33 \pm 16.64$ & .948 \\
\hline & Operative group with complications & $43.13 \pm 14.08$ & $44.38 \pm 14.54$ & .612 \\
\hline & Nonoperative group & $44.98 \pm 11.66$ & $48.53 \pm 11.97$ & .248 \\
\hline \multirow[t]{3}{*}{ SF-36 PCS (Figure 1D) } & Operative group without complications & $31.57 \pm 4.65^{\mathrm{a}}$ & $43.06 \pm 9.63^{\mathrm{a}}$ & $.007^{\mathrm{a}}$ \\
\hline & Operative group with complications & $31.28 \pm 8.54^{\mathrm{d}}$ & $36.62 \pm 9.41^{\mathrm{d}}$ & $.007^{\mathrm{d}}$ \\
\hline & Nonoperative group & $35.85 \pm 9.86$ & $33.97 \pm 11.76$ & \\
\hline \multirow[t]{3}{*}{ SRS-22 (Figure 1E) } & Operative group without complications & $2.67 \pm 0.37^{\mathrm{a}}$ & $3.22 \pm 0.67^{\mathrm{a}}$ & $.026^{\mathrm{a}}$ \\
\hline & Operative group with complications & $2.58 \pm 0.64^{\mathrm{d}}$ & $2.95 \pm 0.89^{\mathrm{d}}$ & $.005^{\mathrm{d}}$ \\
\hline & Nonoperative group & $2.94 \pm 0.80$ & $3.01 \pm 0.86$ & \\
\hline
\end{tabular}

Abbreviations: COMI, Core Outcome Measures Index; ODI, Oswestry Disability Index; SF-36 MCS, Short-Form-36 Mental Component Summary; SF36-PCS, ShortForm-36 Physical Component Summary; SRS-22, Scoliosis Research Society-22.

treatment, even at relatively low impairment levels. ${ }^{25}$ Finally, we have to emphasize that this very decision relies not solely on the patients (and kin) but also on the discretion and advice provided by the physicians and surgeons involved in the management of these patients. In this respect, the physicians and surgeons involved in this study might have had lower disability threshold levels.

As can be expected, elderly patients are prone to have complications with surgical treatment. This study revealed 135 complications (71 major, 64 minor) in 47 patients $(77 \%)$ and 1 death $(1.63 \%)$ in the group of 61 patients who had surgical treatment with 2 year follow-up. There is no doubt that these rates are high and may as well be instrumental in supporting the hypothesis of "this type of surgery in this population is too risky to be justified." Seen from a different perspective, though, our demonstrated rate of complications in this elderly population is not much higher than what has recently been reported for the general ASD population by others. ${ }^{10}$ We may also need to consider that data on the complication rates about conservative treatment as well as normative data on adverse events for this population within these specific age limits are not available. Retrospective data from our database (as well as other, similar databases) may be very accurate in registering the complications and adverse events in surgical patients but are probably not so for these treated conservatively (or not treated at all). Therefore, we do not necessarily have a basis for comparison for the likelihood of complications, even for mortality for other treatment options. It is also important to note that
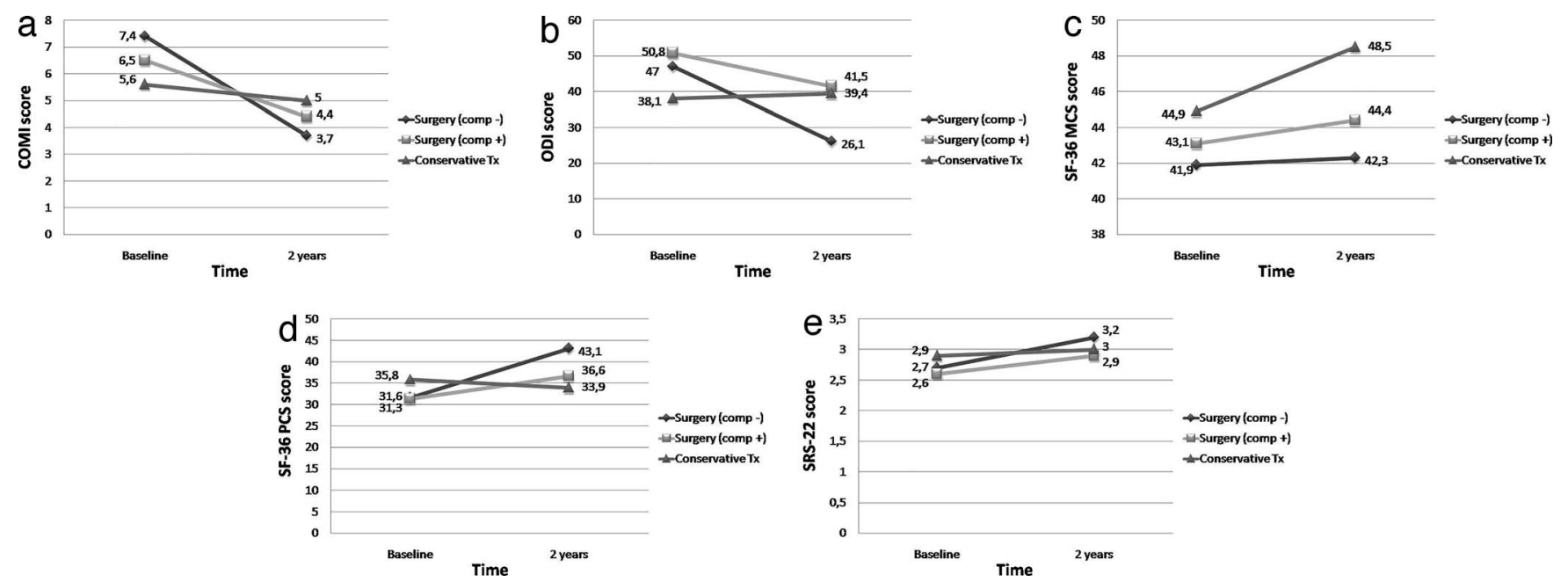

Figure 1. Changes in Core Outcome Measures Index (COMI) (a), Oswestry Disability Index (ODI) (b), Short-Form-36 Mental Component Summary (SF-36 MCS) (c), Short-Form-36 Physical Component Summary (SF-36 PCS) (d), and Scoliosis Research Society-22 (SRS-22) (e) scores from baseline to second-year time points for "operative group with complications," "operative group without complications," and "nonoperative group." 
despite a relatively high complication rate, the surgical patients in this cohort had clinically relevant improvements in their HRQOL measures compared the preoperative baseline levels of the same patient. Moreover, no influence of surgical complexity on complications and HRQOL parameters was detected (Table 7). Based on these, it would be reasonable to think that surgical treatment of ASD appears to be a very reasonable alternative for patients in whom such surgery is indicated.

This being said, it is essential to understand that our results should not necessarily be interpreted as a basis of justification for surgery in each and every elderly person with ASD. Based on their disability and comfort levels, many elderly patients with ASD probably do not require any treatment at all. These patients may not be seeking medical services because of their deformities and hence may not be adequately represented in our as well as similar database(s), but it is clear that these people do not need surgery. On the other extreme, some patients may be too sick to justify recommending a surgery of this magnitude as well. We are not able to identify these patients with a high enough accuracy at this point in time, but as the data from similar studies on elderly community accumulate in the future, clear guidelines on risk stratification and justification of surgery will be available.

We would also like to iterate that although the differences in many preoperative parameters between operative and nonoperative groups' scores appear to be significant, there is also considerable overlap of these populations due to the retrospective nature of this study, which is one of the major limitations. It may be because of this that the specificity of the cutoff values was not what might be called as ideal. Similarly, there are shortages of follow-up of nonoperative patients, an overlap in outcome scores between operative and nonoperative scores, small differences in outcomes between "operative with complications" and "nonoperative" treatment, and a quite high complication rate. Based on this, as also emphasized above, active efforts in decreasing the complication rates in ASD surgery may be warranted so as to increase the positive impact of surgery on HRQOL.

Therefore, the findings of this study should be interpreted as evidence supporting surgical treatment of ASD in a selected ASD population in which both the treating physicians and the patients themselves had collectively decided that such a treatment was justified. And, once the decision is made, the likelihood of clinical improvement is worth mentioning for the aged population of ASD patients.

\section{CONCLUSIONS}

This study has retrospectively evaluated an ASD database and found the decisive factors leading to surgical treatment in patients over 70 years of age. Moreover, the safety and efficacy of surgical treatment modalities were assessed in the same patient population, and the results demonstrate that despite a relatively high incidence of complications (135 complications in 47 patients [77\%] and 1 death [1.63\%] in 61 surgical patients), the likelihood of achieving relevant HRQOL improvement was significantly superior for patients who were treated surgically in the present population. Therefore, the findings of this study should be interpreted as evidence supporting surgical treatment of ASD in a selected population in which both the treating physicians and the patients themselves had collectively decided that such a treatment was justified.

\section{ACKNOWLEDGMENTS}

The abstract was presented at Global Spine Congress 2017 in Milan. The European Spine Study Group is a clinical research group funded by a research grant from DePuy-Synthes.

\section{REFERENCES}

1. Pellise F, Vila-Casademunt A, Ferrer M, et al. Impact on health related quality of life of adult spinal deformity (ASD) compared with other chronic conditions. Eur Spine J. 2015;24(1):3-11.

2. Acaroglu RE, Dede O, Pellise F, et al. Adult spinal deformity: a very heterogeneous population of patients with different needs. Acta Orthopaed. 2016;50(1):57-62.

3. Glassman SD, Berven S, Kostuik J, Dimar JR, Horton WC, Bridwell K. Nonsurgical resource utilization in adult spinal deformity. Spine (Phila Pa 1976). 2006;31(8):941-947.

4. Smith JS, Shaffrey CI, Glassman SD, et al. Risk-benefit assessment of surgery for adult scoliosis: an analysis based on patient age. Spine (Phila Pa 1976). 2011;36(10):817-824.

5. Smith JS, Lafage V, Shaffrey CI, et al. Outcomes of operative and nonoperative treatment for adult spinal deformity: a prospective, multicenter, propensity-matched cohort assessment with minimum 2-year follow-up. Neurosurgery. 2016;78(6):851-861.

6. Youssef JA, Orndorff DO, Patty CA, et al. Current status of adult spinal deformity. Glob Spine J. 2013;3(1):51-62.

7. Smith JS, Shaffrey CI, Glassman SD, et al. Clinical and radiographic parameters that distinguish between the best and 
worst outcomes of scoliosis surgery for adults. Eur Spine J. 2013;22(2):402-410.

8. Bridwell KH, Glassman $\mathrm{S}$, Horton $\mathrm{W}$, et al. Does treatment (nonoperative and operative) improve the two-year quality of life in patients with adult symptomatic lumbar scoliosis: a prospective multicenter evidence-based medicine study. Spine (Phila Pa 1976). 2009;34(20):2171-2178.

9. Acaroglu E, Yavuz AC, Guler UO, et al. A decision analysis to identify the ideal treatment for adult spinal deformity: is surgery better than non-surgical treatment in improving health-related quality of life and decreasing the disease burden? Eur Spine J. 2016;25(8):2390-2400.

10. Smith JS, Klineberg E, Lafage V, et al. Prospective multicenter assessment of perioperative and minimum 2-year postoperative complication rates associated with adult spinal deformity surgery. J Neurosurg Spine. 2016;25(1):1-14.

11. Puvanesarajah V, Shen FH, Cancienne JM, et al. Risk factors for revision surgery following primary adult spinal deformity surgery in patients 65 years and older. $J$ Neurosurg Spine. 2016;25(4):486-493.

12. Daubs MD, Lenke LG, Cheh G, Stobbs G, Bridwell KH. Adult spinal deformity surgery: complications and outcomes in patients over age 60. Spine (Phila Pa 1976). 2007;32(20):22382244.

13. Scheer JK, Hostin R, Robinson C, et al. Operative management of adult spinal deformity results in significant increases in qalys gained compared to non-operative management: analysis of 479 patients with minimum 2-year follow-up. Spine (Phila Pa 1976). 2018;43(5):339-347.

14. Scheer JK, Mundis GM, Klineberg E, et al. Recovery following adult spinal deformity surgery: the effect of complications and reoperation in 149 patients with 2-year follow-up. Eur Spine J. 2016;25(8):2612-2621.

15. Ayhan S, Aykac B, Yuksel S, et al. Safety and efficacy of osteotomies in adult spinal deformity: what happens in the first year? Eur Spine J. 2016;25(8):2471-2479.

16. Glassman SD, Hamill CL, Bridwell KH, Schwab FJ, Dimar JR, Lowe TG. The impact of perioperative complications on clinical outcome in adult deformity surgery. Spine (Phila Pa 1976). 2007;32(24):2764-2770.

17. Sciubba DM, Scheer JK, Yurter A, et al. Patients with spinal deformity over the age of 75: a retrospective analysis of operative versus non-operative management. Eur Spine J. 2016;25(8):2433-2441.

18. Pellise F, Vila-Casademunt A, Nunez-Pereira S, et al. The Adult Deformity Surgery Complexity Index (ADSCI): a valid tool to quantify the complexity of posterior adult spinal deformity surgery and predict postoperative complications. Spine J. 2018;18(2):216-225.

19. Pellise F, Domingo-Sabat M, Alanay A, et al. Impact of radiographic parameters on HRQOL in adult spinal deformity. The "Lordosis Gap" better than lumbar lordosis? Eur Spine J. 2012;21:S269-S337.

20. Obeid I, Boissiere L, Yilgor C, et al. Global tilt: a single parameter incorporating spinal and pelvic sagittal parameters and least affected by patient positioning. Eur Spine $J$. 2016;25(11):3644-3649.

21. Yuksel S, Ayhan S, Domingo-Sabat M, et al. Minimum detectable change (MDC) and minimum clinically important difference (MCID) of health related quality of life parameters in adult spinal deformity. Scoliosis Research Society 52nd Annual Meeting and Course. Philadelphia, PA; 2017.

22. Mannion AF, Porchet F, Kleinstuck FS, et al. The quality of spine surgery from the patient's perspective: part 2 . Minimal clinically important difference for improvement and deterioration as measured with the Core Outcome Measures Index. Eur Spine J. 2009;18(Suppl 3):374-379.

23. Crawford CH III, Glassman SD, Bridwell KH, Berven $\mathrm{SH}$, Carreon LY. The minimum clinically important difference in SRS-22R total score, appearance, activity and pain domains after surgical treatment of adult spinal deformity. Spine (Phila Pa 1976). 2015;40(6):377-381.

24. Bae J, Theologis AA, Strom R, et al. Comparative analysis of 3 surgical strategies for adult spinal deformity with mild to moderate sagittal imbalance. $J$ Neurosurg Spine. 2018;28(1):40-49.

25. Arima H, Carreon LY, Glassman SD, et al. Age variation in the minimum clinically important difference in SRS-22r after surgical treatment for adult spinal deformity - a single institution analysis in Japan. J Orthop Science. 2018;23(1):20-25.

Disclosures and COI: The authors of this article have no competing interests that influence the results and discussion of this article. Cem Karabulut: Grants/research support: Medtronic. Selim Ayhan: None. Selcen Yuksel: None. Vugar Nabiyev: None. Ferran Pellise: Grants/research support: Depuy Synthes, K2M; Consultant: Depuy Synthes. Alba Vila-Casademunt: Grants/research support: Depuy Synthes. Ahmet Alanay: Grants/research support: Depuy Synthes; Consulting: Depuy Synthes, Stryker, Medtronic. Francisco JS Perez-Grueso: Grants/ research support: Depuy Synthes; Consulting: Depuy Synthes Spine. Frank Kleinstuck: Grants/research support: Depuy Synthes. Ibrahim Obeid: Grants/ research support: Depuy Synthes; Consulting: Depuy Synthes, Medtronic, Alphatec. Emre Acaroglu: Grants/research Support: DePuy Synthes, Medtronic, Stryker Spine; Speaker's Bureau: AO Spine, Medtronic, Stryker Spine, Zimmer Biomet; Advisory Board or Panel: AO Spine; Stock/Shareholder: IncredX (self-managed).

Corresponding Author: Emre Acaroglu, MD, Ankara Spine Center, Iran Caddesi, 45/2, Kavaklidere 06700, Cankaya, Ankara, Turkey. Phone: +90 312467 0442; Fax: +90 312467 3915; Email: acaroglue@gmail.com.

Published 31 August 2019

This manuscript is generously published free of charge by ISASS, the International Society for the Advancement of Spine Surgery. Copyright (c) 2019 ISASS. To see more or order reprints or permissions, see http://ijssurgery.com. 